\title{
0 primeiro espectro das protuberâncias solares
}

\author{
M. N. BERBERAN E SANTOS *
}

\section{ANTECEDENTES E PREPARATIVOS}

0 eclipse total do Sol de 18 de Agosto foi o grande fenómeno celeste de 1868 (ver Destaque I). Era esperado com impaciência por astrónomos e físicos, pois seria a oportunidade de aplicar pela primeira vez a recente técnica de Análise Espectral ao Sol eclipsado. Esta técnica, desenvolvida em grande medida por Bunsen e Kirchhoff, mostrara já o seu valor ao levar à descoberta de quatro novos elementos químicos (Quadro I), bem como à identificação de ferro, cálcio, magnésio, sódio, níquel e crómio na atmosfera solar, o que despertara um interesse generalizado.

Os estudos físicos propriamente ditos tinham duas finalidades principais: em primeiro lugar, proceder ao estudo das protuberâncias (ver Destaque II), para determinar a sua dinâmica, estado físico e composição química - tentar-se-ia pela primeira vez obter o seu espectro de emissão; em segundo lugar, pretendia-se obter 0 espectro da camada gasosa acima da fotosfera. Se a teoria de Kirchhoff (sol constituído por um globo sólido incandescente rodeado por uma atmosfera gasosa mais fria) fosse correcta, essa camada fria, que segundo este produzia as riscas de Fraunhofer, apresentaria por si só um espectro semelhante mas invertido, isto é, em que as riscas de absorção se tornavam riscas de emissão. Este espectro de emissão deveria ser observável imediatamente antes e imediatamente depois da totalidade, quando a Lua deixasse ver apenas uma fracção da atmosfera acima do bordo solar.

0 rigor dos cálculos astronómicos de então permitia prever com bastante exactidão os locais onde 0 eclipse seria total (faixa de totalidade), bem como a hora e a duração do mesmo para cada particular dos Almanaques Náuticos e Anuários de Observatórios, publicados com antecedências superiores a um ano. Os pontos mais acessiveis da faixa de totalidade e onde 0 eclipse teria a maior duração (de 5 minutos e 10 segundos a 6 minutos e 47 segundos) situavam-se na Índia, na Península de Malaca e no sul do Cambodja [1-3].

Como em 18 de Agosto se estaria em plena monção de sudoeste, as zonas costeiras à sua mercê ficavam desde logo postas de parte como possiveis pontos de observação. Era o caso de Goa, onde 0 eclipse foi afinal observado, num dia com nuvens mas sem uma gota de chuva [4] (Figura 1).

Eeellpse do sol total e vislrel em Ceas. No dia 18 do corrente haverá ecclipse do sol, e sera total e visivel em Goa. 0 Almanach do ctu de Goa fallando deste ecclipse, diz que começará fallando deste ecclipse, diz que começará
ás $71 / 3$ horas da manhô, passará a ser centrấ ás 8 horas a 26 minutos, será central ao meio dia ís 10 horas e 8 minutos, deixará de ser central ás 11 horas e $\mathbf{1 9}$ minutos, e acabará acs $\mathbf{1 4}$ minutos depois do meio dia. Uma carta de Botrbaim tiz-nos, que o paquete ahi chegado no dia 30 de julho, trouxe os professores e astronomos allemães Spoer, Tietzen, Englemsn, e o professor que dizem ser inglez mr. C. Koppe, os quaes rem expressamente da Europa estudar os phenomeos do proximo ecclipse.

Foram várias as nações europeias que organizaram expedições científicas para 0 estudo do eclipse. Os astrónomos vienenses Weiss e Von Oppolzer',

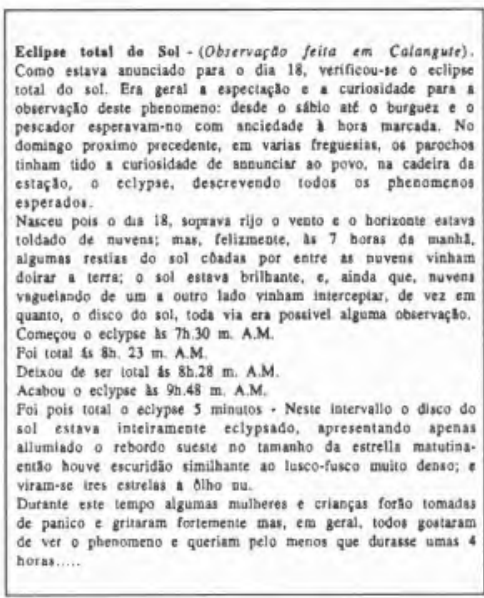

Figura 1 - Noticias publicadas na imprensa goesa, respectivamente em "0 Ultramar" (Margão) de 13/8/868 e em "Índia Portuguesa" (Orlim) de $20 / 8 / 868$

\section{Eclipse total do Sol de 18 de Agosto de 1868}

0 eclipse de 18 de Agosto de 1868 foi considerado 0 eclipse do século, pela sua duração excepcionalmente longa, que atingiu um máximo de 6 minutos e 47 segundos (sendo o limite teórico de 7 minutos e 40 segundos). Um eclipse do Sol é tanto mais longo quanto maior for 0 diâmetro aparente (isto é. visto da Terra) da Lua em relação ao diâmetro aparente do Sol. Este último é mínimo no início do Verão, quando Terra e Sol estão o mais afastados possivel. Em 18 de Agosto, o diâmetro aparente do Sol estava pois próximo do minimo, nesse ano atingido a 1 de Julho. Por outro lado, e mais importante, a Lua atingira nesse mesmo dia o perigeu, isto é, a menor diståncia à Terra, pelo que o seu diâmetro aparente era quase 0 máximo. Além disso, as regiōes onde se daria o eclipse encontravam-se nos trópicos, outro factor favorável a uma duraçāo elevada. A região varrida pelo cone de sombra, dita faixa de totalidade, encontra-se indicada na
Figura 2, redesenhada do Nautical Almanac britânico para 1868. Tal faixa, com uma largura variável com a longitude, mas da ordem dos $250 \mathrm{Km}$, corresponde à região varrida pela intersecção do cone de sombra da Lua com a superficie terrestre. Num dado ponto da faixa, 0 eclipse será total enquanto aquele se mantiver na sombra da Lua. Essa sombra desloca-se sobre a superficie terrestre, de Oeste para Este, a uma velocidade aparente maior ou igual a $1600 \mathrm{Km} / \mathrm{h}$. Com efeito, o movimento da sombra resulta essencialmente da composição da rotaçăo da Terra com o movimento lunar em torno desta (ambos em sentido directo), dependendo também do grau de obliquidade da incidência $e$ ainda da latitude. Resulta destes dois últimos factores que a velocidade mínima se obtém sobre o equador e para incidência vertical ( $\mathrm{Sol}$ no zénite do lugar). Assim, em Áden, onde 0 eclipse ocorreu pouco depois do nascer do Sol, a totalidade teve uma duração de 3 minutos e meio. Na índia, onde foi observado ainda de manhă, teve já uma duração de cerca de cinco minutos e meio. E na 
acompanhados do Tenente de Marinha Rziha, encarregado das medições espectroscópicas, escolheram as imediações de Áden como ponto de observação [5] . Também a expedição fotográfica prussiana, constituida pelos astrónomos Tiele, Vogel $^{2}$, Zenker e Fritsch se estabeleceu em Áden [6]. Mas foi na Península Hindustânica que se concentrou a maioria das expedições. De um total de sete, todas equipadas com espectroscópios, cinco eram inglesas [2,3,7-9]: em Jamkhandi, a da Royal Society, dirigida pelo Tenente Herschel; em Guntur o Major Tennant, da Royal Astronomical Society e do Governo da Índia, comandando um destacamento de sapadores; em Bijapur os Capitães Haig e Tanner, e o matemático do Colégio do Decão Kero Laxuman; em Mongoli (aldeia seis milhas a este de Mulwar, por sua vez 18 milhas a sul de Bijapur) 0 astrónomo Chambers, do observatório de Bombaim; em local indeterminado o astrónomo Pogson, do observatório de Madrasta. Das duas restantes expedições, uma era prussiana, composta pelos astrónomos Spörer, Tietjen, Engelmann e Koppe (em Mulwar) e a outra francesa, do Bureau des Longitudes e Academia das Ciências de Paris, composta pelo físico Janssen e pelo Aspirante Rédier (em Guntur).

$\mathrm{Na}$ Península de Malaca, numa praia a cerca de sessenta léguas de

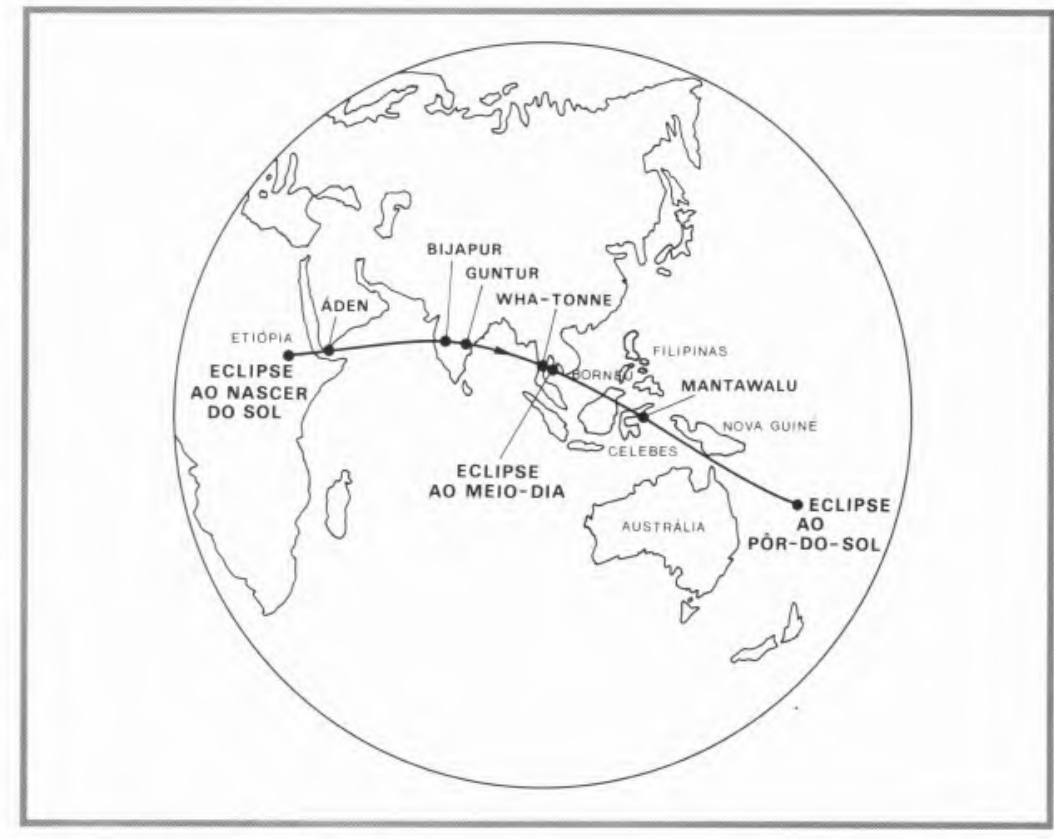

Banguecoque, instalou-se a principal expedição francesa, constituída entre outros pelos astrónomos Stephan, Tisserand e Rayet do Observatório Imperial, estando Rayet incumbido das observações espectroscópicas. Finalmente, em Mantawalu, ilha do golfo de Tomini (Celebes), 0 astrónomo Oudemans, de Amsterdão, na companhia de espanhóis idos expressamente das Filipinas, realizou várias observações não espectroscópicas [10]. 0 eclipse foi ain-
Figura 2 - Linha de centralidade do eclipse de 18 de Agosto de 1868 , indicando-se alguns dos pontos de observação.

da estudado e descrito em muitos outros pontos, nomeadamente na ilha de Bornéu, pelo governador inglês de Labuan, e a bordo de vasos mercantes e de guerra de várias nacionalidades, que se encontravam espalhados ao longo da faixa de totalidade. 0 fenómeno era esperado e sabia-se da sua singularidade.
Descrição do eclipse total do Sol de 18 de Julho de 1860 , presenciado por C. Wolf em Espanha [2]

Peninsula de Malaca, onde ocorreu perto do meio-dia e do equador, teve a duração máxima de 6 minutos e 47 segundos. Em Labuan, no noroeste de Bornéu, ocorreu já de tarde, mas ainda muito perto do zénite. Finalmente, nas Celebes, o Sol estava mais próximo do ocaso, embora ainda alto no céu. Apesar de em Áden 0 eclipse se ter dado pouco depois do amanhecer, e de nas Celebes ter acontecido de tarde (pelas 14.20), a diferença temporal real entre os dois acontecimentos foi muito mais pequena: cerca de 2 horas e 45 minutos, tempo necessário para o cone de sombra passar de um ponto a outro.

Durante a totalidade, o céu não se apresenta completamente escuro, sobretudo junto ao horizonte, devido à luz que penetra fora da zona de totalidade e é dispersa pela atmosfera para 0 interior desta. 0 grau de claridade durante a totalidade é contudo

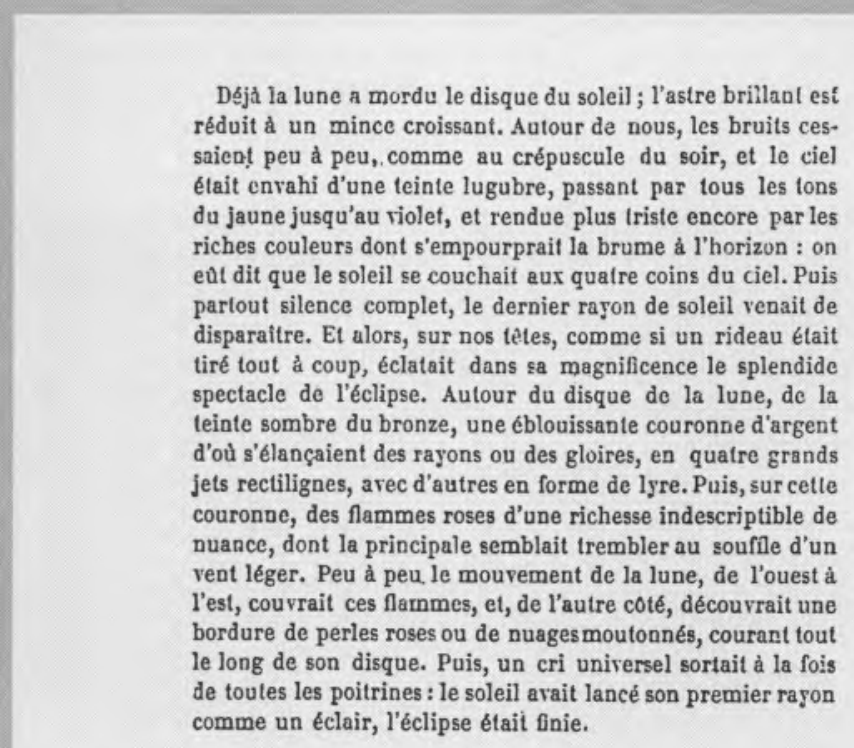

muito variável, dependendo da altura do ponto de observaçāo, da orografia, da proximidade do local em relação à linha de totalidade (centro da oval de sombra) e do estado dispersivo da atmosfera durante 0 eclipse. Pode no entanto ser tal que seja impossivel ler e distinguir objectos, como sucede numa noite sem luar. 


\section{RELATOS DAS EXPEDIÇÕES PRINCIPAIS}

A expediçāo austríaca largou de Trieste, porto de mar do Império AustroHúngaro, rumo a Alexandria [5] . Daí seguiu para Suez presumivelmente de comboio, a partir do Cairo (o canal só seria inaugurado no ano seguinte), onde tomou novo barco para Áden. A viagem pelo Mar Vermelho foi difícil de suportar, pela conjugação de humidade e temperatura elevadas, e da frequente falta de vento. Em Áden, os astrónomos (austríacos e prussianos) foram bem acolhidos pelo governador inglês, tendo-Ihes sido disponibilizados homens da guarniçāo e serviçais nativos. A conselho de oficiais ingleses, escolheu-se como ponto de observação uma elevação não longe da cidade. A ligação logistica era feita por uma caravana diária de dromedários e solipedes. No dia do eclipse, que em Áden se dava logo após amanhecer, 0 céu matinal apresentava-se muito nublado. As observaçōes só puderam fazer-se durante pequenas abertas, e, embora se tenham observado e medido as protuberâncias, a análise espectral das mesmas foi um fracasso. A missão prussiana, por seu lado, pôde tirar três fotografias, das quais apenas uma (Figura 3) saiu em boas condições [3] .

A expedição da Royal Society, dirigida pelo Tenente Herschel (1837-1921, filho e neto de astrónomos distintos),

Figura 3 - Aspecto do eclipse, tal como se apresentou em Áden. Gravura executada a partir das fotografias de Vogel e Fritsch [2]

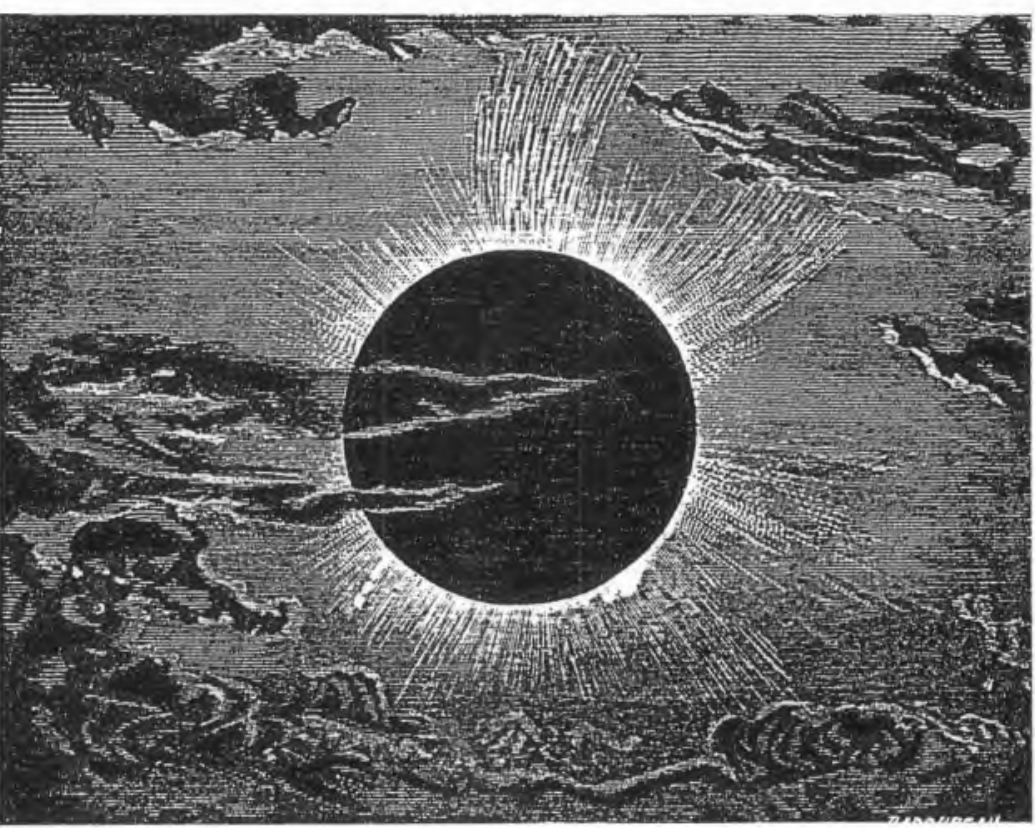

estabeleceu-se em Jamkhandi, no planalto do Decão. Uma vez chegado à Índia , Herschel estudara a distribuição espacial da precipitação durante 0 mês de Agosto e concluira que Bijapur e Jamkhandi eram dos locais onde menos chuva caía. Os oferecimentos de hospitalidade por parte de um chefe local, residente em Jamkhandi, levam-no a optar por esta localização. 0 grosso da expedição parte transportando os instrumentos, um observatório desmontável e restante equipamento. Para percorrer as 390 milhas que a separam de Jamkhandi, demora 31 dias, 0 que Herschel considera aceitável, dada a inexistência de estradas e o tempo adverso. Ele próprio parte a 1 de Agosto, para chegar a 14. Há que montar 0 observatório e testar os instrumentos, quase sempre com céu nublado. Por fim, chega o dia do eclipse. Quinze segundos antes da totalidade, uma espessa nuvem encobre o Sol. Mas alguns segundos depois da totalidade, 0 Sol eclipsado estava de novo visivel e distinguia-se uma longa protuberância "em forma de dedo" $[9,11]$

Apontando-Ihe a luneta, a imagem espectroscópica foi imediatamente a de três riscas brilhantes (vermelha, laranja e azul), sem qualquer espectro contínuo sobreposto. Emocionado, Herschel grita ao assistente "vermelho, verde, amarelo", pensando ter dito as cores correctas. Após algumas hesitações, e apesar das nuvens que se sucediam, interrompendo de quando em quando as observações, Herschel procedeu à determinação do finalmente de Bangalore em 7 de Julho, comprimento de onda das riscas, embora sem grande rigor. Vermelha e azul seriam próximas das riscas $\mathrm{C}$ e $\mathrm{F}$ do hidrogénio, respectivamente, e a laranja parecia coincidir com a risca $D$ do sódio. Mas para o grau de precisāo evidenciado, a identificação certa das riscas observadas com as riscas de referência não era possível. Concluia-se no entanto que as protuberâncias eram formadas por gases incandescentes.

Foi nas ruínas da antiga cidade fortificada de Bijapur que a missāo de Haig se instalou. A estação de observação escolhida era uma sólida torre de 20 metros de altura e quase outros tantos de diâmetro, no alto da qual ainda se encontravam dois velhos canhões, um dos quais com mais de 9 metros de comprido. 0 vento era muito forte, 0 que prejudicou bastante as observações, tendo chegado mesmo a derrubar uma luneta. 0 início da totalidade, pelas 9 da manhã, nāo foi visível, devido à interposição de nuvens. Mas pouco depois 0 Sol eclipsado apresentava-se a descoberto e Haig de imediato aponta o pequeno espectroscópio portátil de que dispunha a duas protuberâncias próximas, cujo espectro, idêntico, apresenta duas riscas, uma vermelha e outra dourada. 0 espectro da coroa, também observado, era de fraca intensidade mas continuo.

A missão germânica, em Mulwar, teve pouca sorte com as condições atmosféricas, e apenas pôde ver o Sol eclipsado durante escassos cinco segundos, só tendo tido tempo para medir a dimensão angular das protuberâncias. Também 0 astrónomo Chambers nada conseguiu observar, em consequência de um manto cerrado de nuvens. Por sua vez, Pogson observou igualmente 0 espectro de emissão das protuberâncias, observando $F, D$ ou próxima de $D$, e duas outras riscas entre $D$ e $E$, mas não parece ter publicado os seus resultados.

A expedição dirigida pelo Major J.F. Tennant (1829-1916) obteve também resultados positivos. As observações espectroscópicas, levadas a cabo pelo próprio Tennant, incidiram sobre a grande protuberância, a que chamou "The Great Horn". 0 seu espectro apresentava várias riscas, uma vermelha, uma laranja, outra verde, múltipla, e ainda outra, difícil de ver, no azul. A risca vermelha exerceu sobre ele um fascinio especial: "One line in the red was so beautiful that it needed an effort to turn my attention to anything else" [7] . A atribuição das riscas foi mais uma vez algo incerta: $C$, a vermelha; D, 


\section{HÁ TRÊS GerAÇOEES}

\section{Oue Portugal Cresce Connosco}

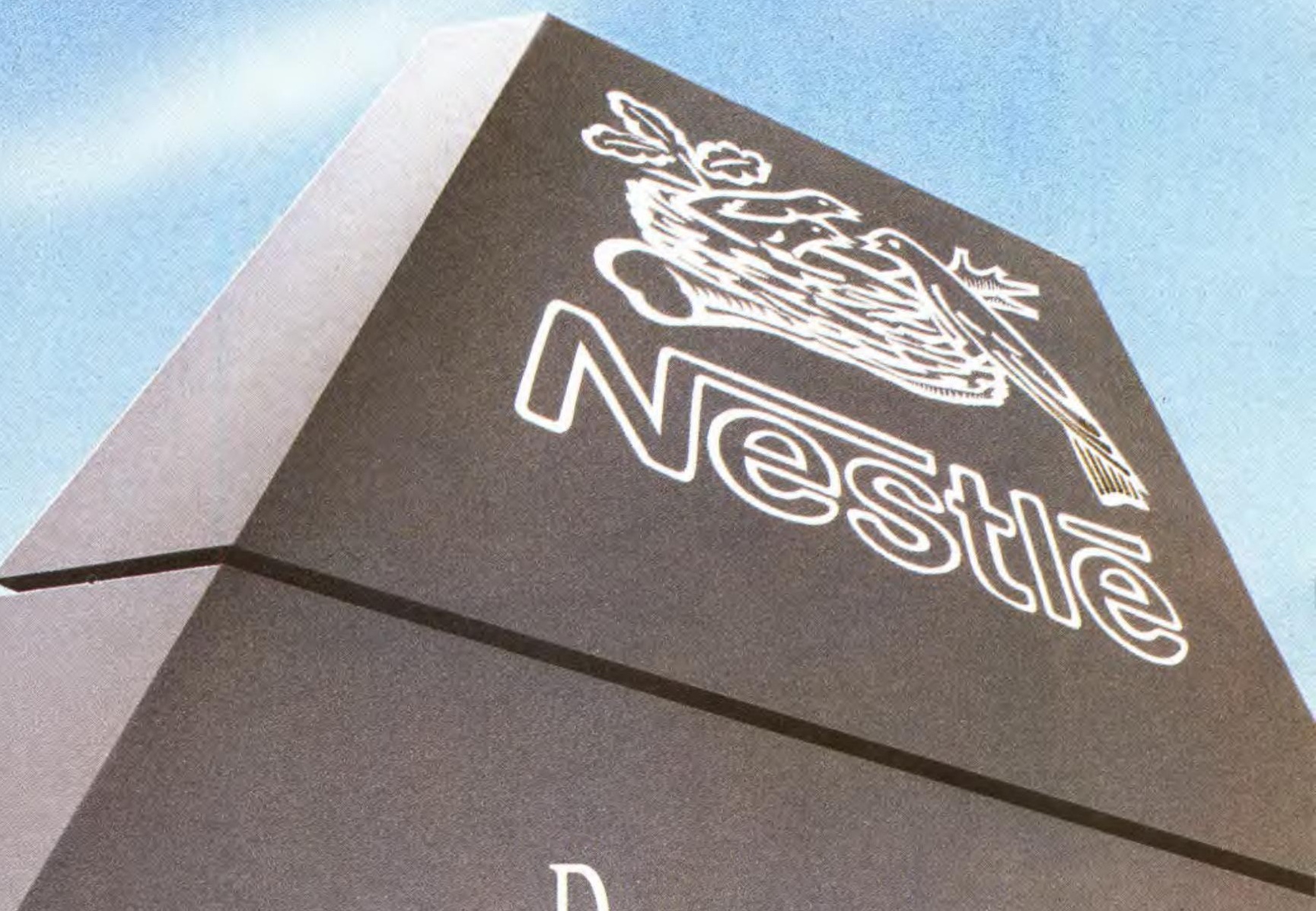

esde finais

do século passado que

milhares de portugueses nascem e crescem com a qualidade Nestlé.

Qualidade que os acompanha a partir dos primeiros passos, através da mais variada gama de produtos alimentares. Equalidade que, geraçāo após geração, os leva a preferir sempre Nestlé, contribuindo para que, também nós, vamos crescendo com os portugueses.

Nestle. Crescendo consigo.

Nestlé Portugal, S.A. 


\section{II. $\mathbf{O}$ Sol}

0 Sol tem uma estrutura e dinâmica complexas, ainda incompletamente conhecidas. É constituido quase exclusivamente por hidrogénio e hélio; em percentagem molar, tem-se $90 \%$ de hidrogénio, $9 \%$ de hélio e $1 \%$ dos restantes elementos (principalmente carbono, azoto, oxigénio, néon, magnésio, silicio e ferro). 0 seu núcleo é extremamente denso (cerca de $10^{2}$ $\mathrm{g} / \mathrm{cm}^{3}$ ) e encontra-se a uma temperatura de 15 milhões de Kelvin. É aí que o hidrogénio é lentamente convertido em hélio, numa sequência de

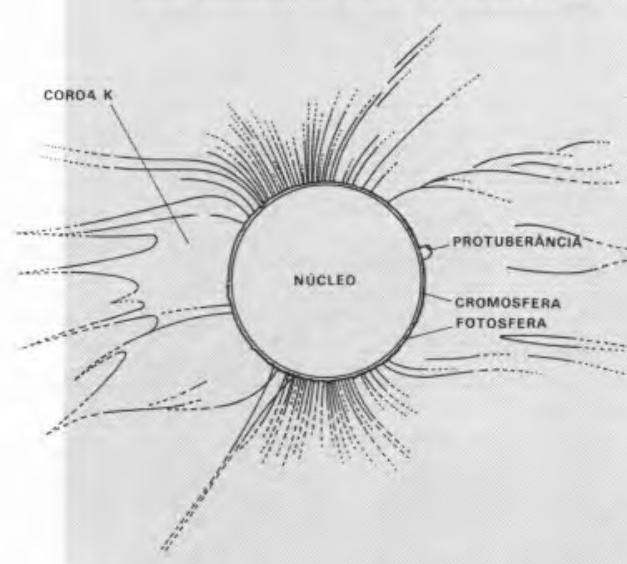

Representaçāo esquemática da estrutura solar reacções nucleares. A energia libertada sob a forma de radiação difunde-se até à região superficial do Sol, num processo que demora vários milhares de anos. Ao atingir esta, escapa-se finalmente para 0 espaço, chegando por exemplo à Terra em 8 minutos. A camada solar superficial, ou fotosfera, a partir da qual os fotões saem para 0 exterior e que é pois a superfície visível do Sol, tem uma densidade muito baixa $\left(-10^{-4} \mathrm{~atm}\right)$ e uma temperatura de aproximadamente $5800 \mathrm{~K}$, emitindo um espectro contínuo muito semelhante ao do corpo negro a essa temperatura. Essa emissão é sobretudo devida ao iāo $\mathrm{H}^{\text {}}$, que se forma com facilidade dada a abundância de átomos de hidrogénio e de electrōes livres provenientes de metais ionizados. Esta emissão contínua apresenta contudo diminuições abruptas de intensidade a certos comprimentos de onda São as chamadas riscas de Fraunhofer (observadas por este em 1814), em número superior a 26.000 mas das quais apenas um pequeno número é relativamente marcado. Estas riscas devem-se à presença de uma zona exterior mais fria, que absorve radiação mas emite menos do que a $5800 \mathrm{~K}$. As riscas escuras correspondem assim aos comprimentos de onda de absorção dos átomos (e moléculas diatómicas) presentes nessa zona mais fria. 0 espectro solar observado na Terra tem ainda outras riscas escuras adicionais na região do visivel ditas telúricas, pois sāo devidas à absorção pelos gases atmostéricos terrestres, sobretudo
$\mathrm{O}_{2}$ (transiçōes singuleto-tripleto) e $\mathrm{H}_{2} \mathrm{O}$ (transiçōes vibracionais). A temperatura da atmosfera solar decresce com a altitude até ao valor minimo de $4200 \mathrm{~K}$ a algumas centenas de quilómetros, para recomeçar a subir depois, atingindo $10.000 \mathrm{~K}$ a cerca de $2000 \mathrm{Km}$. A camada entre 0 mínimo e os $10^{4} \mathrm{~K}$ é designada por cromosfera (nome devido a Lockyer), pois tem uma cor rósea, resultado da predominância no visivel da emissão correspondente à risca $\mathrm{C}(\mathrm{H} \alpha)$ do hidrogénio atómico. 0 espectro de emissão da parte inferior da cromosfera, observável por breves instantes imediatamente antes $e$ imediatamente depois de um eclipse total, e dito por isso espectro-relâmpago, reproduz qualitativamente 0 espectro de Fraunhofer, mas em riscas briIhantes. Acima da cromosfera tem-se a última e mais extensa camada: a coroa. Extremamente rarefeita $\left(<10^{-12} \mathrm{~atm}\right)$, a sua região interna (coroa K), que se estende até cerca de 2 raios solares (1.4 milhões de $\mathrm{Km}$ ) tem uma temperatura elevadissima: cerca de 2 milhões de kelvin. Nessas condiçōes, predominam os electrões livres e os elementos em graus de ionização elevados, isto é, tem-se um plasma. 0 hidrogénio $\mathrm{e}$ 0 hélio, por exemplo, encontram-se predominantemente na forma $\mathrm{H}^{+}$e $\mathrm{He}^{2+}$, enquanto que ferro, niquel e cálcio estão, entre outras, nas formas $\mathrm{Fe}^{13+}, \mathrm{Ni}^{13+}$ e $\mathrm{Ca}^{12+}, 0$ espectro da ténue emissão da coroa Ké contínuo, sendo o resultado da dispersão da radiação fotosférica pelos electrões livres. Contudo, não apresenta riscas de Fraunhofer, pois como a temperatura é muito a laranja; e talvez b (magnésio), a verde. Concluiu assim que "a protuberância era formada por vapores incandescentes, compostos por hidrogénio, sódio e magnésio". Verificou-se ainda que a emissão era despolarizada, ao contrário da da coroa, que apresentava além disso um espectro contínuo. Foram obtidas seis fotografias do Sol eclipsado, com protuberâncias bem visiveis (Figura 4).

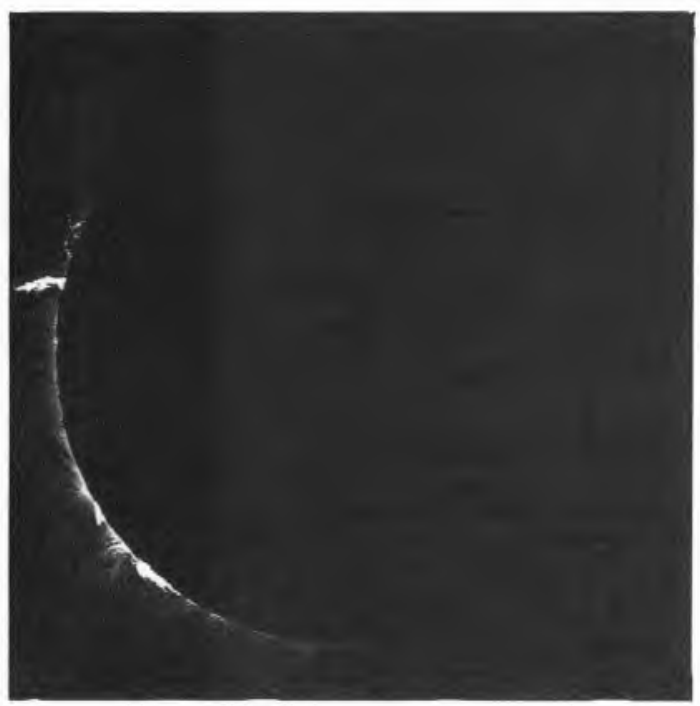

A algumas centenas de metros de Tennant estava a estação de observação de Pierre Janssen (1824-1907). Viajando de França a Madrasta no paquete "L'Impératrice", da Mala Imperial, e depois em novo vapor para Masulipatão, destino previsto da expedição, Janssen acabou por escolher Guntur, mais para 0 interior. Situada a meia distância entre os contrafortes dos Gates Orientais e a costa do Índico, permitiria em princípio evitar quer as brumas maritimas, quer as nuvens de montanha. Guntur havia sido efémera possessão francesa no Séc. XVIII, e ainda aí viviam descendentes dos colonos iniciais, um dos quais, rico comerciante de algodão, pôs o terraço da sua casa à disposição de Janssen para que nele fosse montado o equipamento [12]. Segundo nos relata Janssen, o tempo apresentou-se excepcionalmente chuvoso e enevoado até à véspera. Felizmente, a 18 de Agosto 0 dia nasceu com o céu quase limpo, e assim se manteve até ao termo do eclipse. Em estado de grande tensão, Janssen e os seus colaboradores, em que se incluíam fami-

Figura 4 - Fotografia do Sol eclipsado, obtida em Guntur (tempo de exposição: $5 \mathrm{~s}$ ) [7]. liares do anfitrião, realizavam afanosa mente as medições programadas à medida que 0 eclipse se ia desenrolando. A observação do bordo do disco solar com 0 espectroscópio (através da luneta), apresentava o espectro de riscas escuras sobre fundo brilhante caracteristico. Mas eis que se atinge a totalidade, $\mathrm{e}$ se fazem trevas. No mesmo instante, 0 espectro muda por completo. Sobre um fundo cinza claro, destacam-se agora, nítidas, uma, duas .... cinco ou seis riscas brilhantes de várias cores: vermelha, amarela, verde, azul, violeta [12]. 0 espectro é idêntico para duas protuberâncias que se destacam do disco momentâneamente negro. Uma tem a forma de uma longa língua de fogo. A outra, assemelha-se a uma cadeia de montanhas nevadas, vista ao pôr-do-sol [12]. Estava atingido 0 objectivo da expedição. E era tempo, pois o céu voltava a cobrir.

Dos resultados obtidos, Janssen concluia que as protuberâncias eram gasosas, e de composição constante: havia observado 0 mesmo espectro em duas protuberâncias separadas de muitos milhares de quilómetros. Deduzia ainda que 0 hidrogénio era 0 elemento dominante pois as riscas vermelha (res- 
elevada 0 efeito de Doppler sobre o continuo anula-ascompletamente. Além do contínuo fotostérico, observam-se riscas de emissão de metais (e alguns não metais) em estados de ionizaçāo elevados (Quadro II).

As protuberâncias solares são elevacões de matéria gasosa $\left(-10^{-8} \mathrm{~atm}\right)$ a grande altura (vários milhares de quilómetros), com temperaturas próximas das cromostéricas, constituindo como que prolongamentos temporários desta no interior da coroa. Nos eclipses, apresentam-se como zonas luminosas no bordo da Lua, destacando-se contra 0 céu escuro. As protuberâncias formam-se frequentemente como gigantescos arcos ou séries de arcos de matéria cujas bases mergulham na fotosfera e que depois evoluem lentamente, durante semanas ou meses (protuberâncias estacionárias), até que terminam por ejecçōes bruscas e violentas, com velocidades que atingem centenas de quilómetros por segundo e temperaturas muito elevadas. Estas erupçóes são consequência da reorganizaçāo dos campos magnéticos que sustentavam as protuberâncias. Pensa-se que a energia libertada no decurso das ejecçōes de matéria poderá ser a causa do aquecimento da coroa. As protuberâncias normalmente observadas são casos raros e extremos que envolvem grandes massas de matéria, provindo a maior parte da energia de tenómenos análogos mas em menor escala e muito mais frequentes.

sem dúvida as $\mathrm{C}$ e $\mathrm{F}$ de Fraunhofer. Logo no dia seguinte envia um telegrama ao presidente do Bureau des Longitudes (que chega a 22), talvez a primeira noticia recebida na Europa sobre 0 eclipse: "Eclipse observed, Protuberances, Spectrum very Remarkable and inexpected, Protuberances gaseous nature" [13].

Tal como Guntur, a praia de Wha-Tonne, na costa leste da península de Malaca, estava abrigada da monção de sudoeste por uma cadeia montanhosa. 0 local era inóspito, quase sem vida animal e sem água potável. Uma densa floresta pantanosa chegava até à praia, banhada pelas água tépidas do Golfo de Sião. Por ordem do rei siamês, Rama IV ${ }^{3}$, haviam sido erguidas uma paliçada e algumas casas de bambu para alojar os convidados europeus. Um observatório temporário fora construído pelos carpinteiros da canhoneira "Le Frêlon", que precedera a missão científica. Desde 0 dia 14 de Agosto, o rei do Sião, que no dizer zombeteiro de Rayet " se piquait fort d'astronomie", instalara-se com a sua numerosa corte a um quilómetro a norte da expedição francesa. 0 cenário era singular, naquele local habitualmente deserto: para além do intenso movimento em terra, fun- deavam no mar quinze navios a vapor do rei, e ainda o navio de transporte francês e um barco inglês. No dia do eclipse, as várias fases do mesmo (contactos) foram saudadas por outros tantos tiros de canhão, comandados pessoalmente por Sua Majestade. Segundo Rayet confessa com alguma malicia, os astrónomos franceses tinham previamente comunicado esses instantes ao astrónomo real e chegado mesmo ao ponto de acertar um dos relógios de Rama IV [3]

0 dia 18 amanhecera com 0 céu limpo. Mas às nove horas 0 Sol desaparecera por detrás de nuvens carregadas de chuva, e o tempo piorava cada vez mais. 0 primeiro contacto foi invisivel. No entanto, dez minutos antes do segundo contacto (início da totalidade), uma aberta descobre o Sol. Felizmente, essa aberta perdurará até ao terceiro contacto (fim da totalidade), permitindo a observação completa da parte mais importante do eclipse.

Os resultados espectrais obtidos pelo jovem astrónomo Georges Rayet (1839-1906) foram, de todos, talvez os mais completos, o que se deveu à conjugação de quatro factores: maior abertura do telescópio usado (um reflector de $20 \mathrm{~cm}$ ); espectroscópio relativamente pouco dispersivo; maior obscuridade durante a totalidade; maior duração da totalidade. Assim que se dá a obscuridade total, Rayet dirige a fenda do espectroscópio para a protuberância "em forma de chifre", e vê aparecer um espectro de nove riscas brilhantes, muito intensas, sobre um fundo cinza-claro, 0 que 0 faz soltar um grito de contentamento [3] . Pela posição das riscas, identifica-as - à excepção de uma - com riscas de Fraunhofer, respectivamente $B, D, E, b, F$, duas riscas de $G$ [13] (estas atribuições são imprecisas; B era por exemplo C). Rayet dirigiu em seguida 0 seu telescópio para outro grupo de protuberâncias, em forma de cadeia montanhosa, obtendo um espectro semelhante ao primeiro, com excepção de uma risca violeta que desta feita não era visivel. Concluiu assim que as protuberâncias eram jactos de matéria gasosa incandescente, "chamas de um fenómeno químico de extrema potência", e de composição química algo variável. A expedição do Observatório levantou ferro de Wha-Tonne logo a 19 de Agosto, abandonando o mais depressa possível a costa insalubre. Apesar disso, vários expedicionários viriam a padecer por longos meses de febres intensas contraídas em terra. Rama IV
ÉCLIPSE DE SOLEIL DO 18 AOLT. - Trois grandes expéditions scientifịques avaient été envoyées dans l'Inde pour y observer celte éelipse, la plus imporlante du sićcle. L'expédition anglaise, la plus nonibreuse des trois, organisée par la Société royale de Londres et l'observatoire de Greenwich, a euvoyé des dépéches télégraphiqucs, cetle scmaine, à Association britannique pour l'avancement des sciences, en ce m:oment en session à Norwich. II parait que quelques nuages ont géné ses observations. Des deux expéditions francaices, celle qui a dé pervations. Des deux expedtions françaises, celle qui a été organisée par Tobservatoire de Paris n'a plas cncore doliné de ses nouvelles. On a çu, au contraire, une depeche tele graphique de M. Jaussens, charge par le Dureau des longitudes d'observations danalyse spectrale et de physique du globe. $M$. Janssens annonce que le spectre des protubérances rosacées lui a présenté des particularités inattendues, et démontro la nature gazeuse de ces corps.

Figura 5 - Notícia publicada na 'Revue des Cours Scientifiques*

faleceria em Outubro desse ano, também em consequência de doença contraída em Wha-Tonne.

\section{BALANÇO CIENTÍFICO}

As observações espectroscópicas efectuadas permitiam concluir da natureza gasosa das protuberâncias, 0 que concordava com a ausência de polarização. As riscas observadas mostravam além disso que o hidrogénio era um dos constituintes principais, se não o principal, das mesmas [12,15] . A comparação das protuberâncias observadas em diversos pontos da faixa de totalidade, $\mathrm{e}$ portanto em diversos instantes,fornecia além disso as primeiras informações sobre a sua evolução temporal [16] . 0 outro grande resultado das missōes, embora negativo, era também importante. Ninguém pretendera ter visto 0 espectro de emissão devido à "camada inversora" de Kirchhoff, o que implicava uma espessura muito pequena ou nula para esta[2]. ${ }^{4}$ Muitas noções sobre a estrutura e dinâmica do Sol mantinhamse contudo incorrectas, e só muito mais tarde viriam a ser rectificadas. Por exemplo, persistia a ideia de 0 espectro continuo de emissão da fotosfera ser devido à combustão de hidrogénio (molecular ${ }^{5}$ em condições de pressão elevada.

0 Sol e as outras estrelas seriam assim fornalhas imensas, hipótese que vinha aliás já do Século XVIII (o século do oxigénio e das combustões) e está expressivamente cristalizada na constelação austral a que 0 astrónomo La Caille (1713-1762), aliás professor de Lavoisier, chamou Fornax Chemica.

\section{UM DESENVOLVIMENTO INESPERADO}

Não era satisfatório poder observar as protuberâncias apenas durante os breves momentos de obscuridade de um 

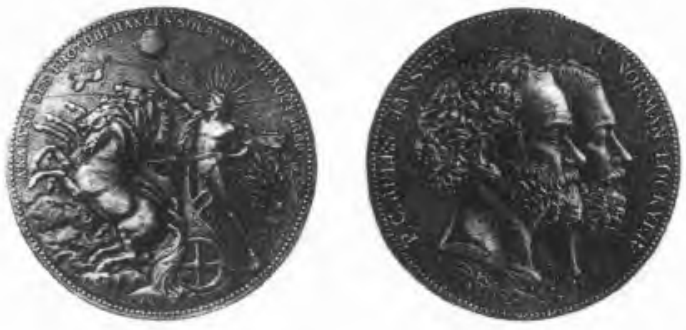

Figura 6 - Medalha cunhada pela Academia das Ciências de Paris para comemorar 0 novo processo de estudo das protuberâncias, desenvolvido independentemente por Janssen e Lockyer. Pierre César Jules Janssen principiou por trabalhar num banco, tendo-se doutorado em 1860. Dirigiu várias expediçōes cientificas para 0 estudo do magnetismo terrestre (Perủ 1857, Açores 1867), da Fisica do Sol e da atmosfera (Itália 1861, Índia 1868). Fundou os observatórios de Meudon (onde tem uma estátua) e do Monte Branco. Sir Joseph Norman Lockyer começou por ser funcionário do British War Office, dedicando-se à astronomia como amador. Fundou em 1869 a revista Nature. Dirigiu os observatórios de South Kensington e Sidmouth. Organizou oito expediçōes para a observação de eclipses. Foi autor de várias obras sobre espectroscopia e astrofísica, bem como de um livro sobre golfe.

eclipse total. Por um lado, estes são raros (dois por ano, no máximo) e apenas observáveis em faixas do globo nem sempre favoráveis. Por outro, o estudo da dinâmica das protuberâncias e restante atmosfera solar precisava de maiores tempos de estudo continuado. Na noite de 18 para 19 de Agosto, Janssen não adormece, pensando sem cessar no modo de ultrapassar a dificuldade. E encontra a solução. Bastava usar uma fenda suficientemente estreita, disposta tangencialmen-

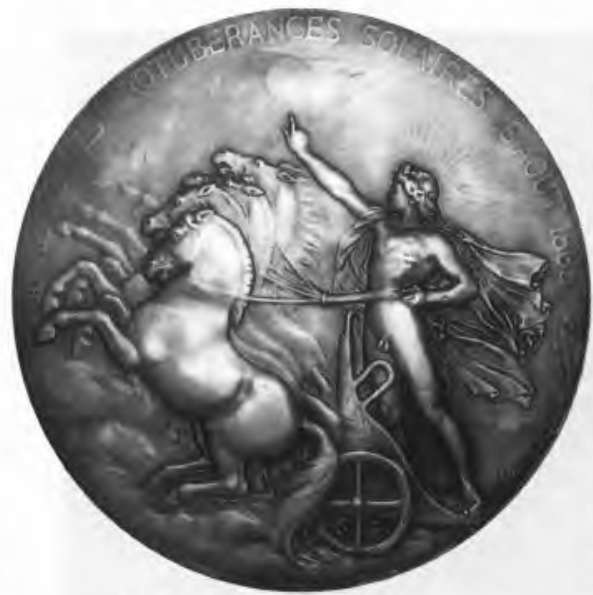

III. Um medalhão alusivo

Existe nas Iojas da Imprensa Nacional-Casa da Moeda (INCM) um quadro circular em cobre, de $23 \mathrm{~cm}$ de diâme- te ao disco solar, para apenas captar a radiação devida à protuberância, isolando-a do fundo intenso fotosférico. Janssen está a pé desde as três da manhã de 19 de Agosto, impaciente por testar a sua técnica. Pelas 10 horas, assim que o Sol irrompe por entre a neblina matinal, reencontra imediatamente as riscas brilhantes que entrevira fugazmente na véspera. Que alegria não terá sentido!

Depois, realiza até 4 de Setembro observações quase ininterruptas das protuberâncias, como se de um eclipse de 17 dias se tratasse.

Entretanto, em Inglaterra, o astrónomo Joseph Lockyer (1836-1920) vinha fazendo desde há quase dois anos e meio tentativas semelhantes mas sempre sem êxito o que levara a concluir (e publicar) não serem as protuberâncias gasosas. Os relatos do eclipse recebidos na Europa, em especial os de Rayet, Herschel e Tennant, mostraram-lhe que estava errado. Atribuía agora os seus próprios insucessos ao pouco poder dispersivo do espectroscópio que usara. Um novo aparelho, construído expressamente para a observação do eclipse mas cuja construção e uso se tinham atrasado devido a doenças graves, tanto sua como do fabricante, ficou finalmente pronto e testado em 20 Outubro de 1868. Ainda na manhã desse mesmo dia, no seu observatório particular, situado no jardim da sua casa em Wimbledon, Lockyer consegue ver o espectro de emissão de uma protuberância. Este apresenta três riscas: $\mathrm{C}$ e $\mathrm{F}$, devidas ao hidrogénio, e uma terceira, próxima de $D$

tro, representando Apolo e o seu carro em baixo-relevo. 0 filho de Zeus aponta um disco solar onde são visiveis protuberâncias tais como no-las descrevem os observadores do eclipse de 18 de Agosto de 1868. Encimam os dizeres: Analyse des Protuberances Solaires. 18 Aout 1868.

Não pudémos estabelecer a origem e motivação primitivas da Casa da Moeda para a feitura deste "galvano" (chapa obtida por galvanoplastia). A matriz existente na $\mathrm{CM}$ é no entanto bastante antiga. A presente série, com 2 ou 3 anos, obedeceu a critérios puramente estéticos.

0 "galvano" é uma reprodução, ampliada, de uma das faces da medalha que a Academia das Ciências de Paris mandou cunhar em comemoração do feito de Janssen e Lockyer (Figura 6). mas não coincidente com esta, "diferindo de 8 ou 9 graus da escala de Kirchhoff" [17]. No mesmo dia em que o relato de Lockyer chega à Academia das Ciências de Paris, e com um intervalo de poucos minutos, é recebido o primeiro relato de Janssen, datado de 19 de Setembro, em que esta apresenta o mesmo método de observação das protuberâncias no Sol normal [18].

0 relatório completo de Janssen [19] , datado de 3 de Outubro, só chegará em 1869 à Academia, em consequência de um arreliador erro postal.

Põe-se desde logo a questão da prioridade da descoberta: Lockyer ou Janssen? Embora a ideia tivesse sido avançada primeiro por Lockyer, os resultados negativos obtidos tinham-no feito chegar a conclusões incorrectas, e só as observações alheias feitas durante 0 eclipse 0 haviam levado de novo ao bom caminho. Além disso, a primeira observação de Janssen (19 de Agosto) era sem dúvida anterior à de Lockyer (20 de Outubro).

A Academia das Ciências de Paris, pela voz de H. Faye [20], concluiu pois que "em vez de dividir os méritos da descoberta, enfraquecendo-os, é preferivel atribuir indistintamente a sua honra aos dois homens de ciência que, separados por vários milhares de léguas de distância, tiveram a felicidade de perscrutar 0 intangível e 0 invisível pelo talvez mais espantoso meio de observação jamais concebido pelo engenho humano ".

Por esta descoberta, e entre outras distinções, Janssen e Lockyer receberam em conjunto a medalha de ouro da Academia das Ciências de Paris. (Figura 6; ver Destaque III).

Outros astrónomos haviam imaginado um método alternativo de observação das protuberâncias e cromosfera com um Sol não eclipsado. Pouco depois dos resultados de Janssen e Lockyer serem conhecidos, Huggins recorda que propusera e tentara já o uso de um filtro monocromático. Como a emissão das protuberâncias se concentrava em algumas riscas intensas, deveria ser possível observá-las anulando o contínuo fotosférico por meio de um filtro que apenas deixasse passar radiação com o comprimento de onda de uma das riscas. Também Herschel tivera a mesma ideia após observar as protuberâncias. Mas as dificuldades de construção de um tal filtro só viriam a ser ultrapassadas por Lyot em 1933. 
artigos

\section{UM NOVO ELEMENTO?}

A importância da pequena diferença de comprimentos de onda (menos de $2 \mathrm{~nm}$ ) entre a risca amarela/laranja solitária das protuberâncias e a risca $D$ dupla do sódio não passou despercebida. Assinalada desde 20 de Outubro por Lockyer, a divergência foi rapidamente confirmada e quantificada por vários astrónomos, entre eles o Padre Secchi, S.J., do Collegio Romano [21,22] e Rayet [23] . Também Janssen, ainda na Índia, em Nota datada de 19 de Dezembro [24], refere, talvez forçadamente, ter constatado o mesmo desde 0 dia do eclipse, mas não dando sequer o comprimento de onda da nova risca, ao contrário de Secchi e Rayet $(588.0 \mathrm{~nm}$ e $587.4 \mathrm{~nm}$, respectivamente, bastante próximos do valor correcto, $587.6 \mathrm{~nm}$; para comparação, note-se que o dupleto do sódio fica a $589.0 \mathrm{~nm}\left(\mathrm{D}_{2}\right)$ e $\left.589.6 \mathrm{~nm}\left(\mathrm{D}_{1}\right)^{6}\right)$.

Rayet é aliás o primeiro a aventar a hipótese de a nova risca amarela, dita $\mathrm{D}_{3}$. ser devida a um gás desconhecido $[14,23]$. Frankland e Lockyer, por seu lado, inclinam-se mais para que ela seja devida ao hidrogénio [24]. Ao mesmo tempo, Lockyer avança um nome para a substância produtora da risca, e que ele tenta sem sucesso reproduzir em laboratório com hidrogénio: "for laboratory use, the substance which gave rise to the line in the yellow, I named helium." [25] (ver Destaque IV). Lockyer verá depois 0 hélio como uma forma de hidrogénio estável a altas temperaturas $[25,26]$. Com efeito, foi proponente e defensor acérrimo da teoria da evolução inorgânica, segundo a qual os elementos se dissociariam em formas cada vez mais simples, à medida que a temperatura se elevasse. Hoje reconhecemos nessas formas sucessivos estados de ionização de vários elementos.

A existência de uma nova substância, desconhecida na Terra, fora proposta e recebida com reserva. As pressões e temperaturas no Sol poderiam ser tais que a risca pertencesse a um elemento conhecido, tal como o hidrogénio. A situação era de alguma incerteza, como 0 reconhecia $W$. Thomson (mais tarde Lord Kelvin) em 1871, ao afirmar, em sessão da British Association "Frankland and Lockyer find the yellow (sic) prominences to give a very decided bright line not far from $D$, but hitherto not identified with any terrestrial flame. It seems to indicate a new substance, which they propose to call Helium" [27] .

0 eco da descoberta junto dos quí-

micos foi quase nulo. Num tratado de Química de 1889 [28] refere-se 0 espectro das protuberâncias para se dizer que estas apresentam "riscas brilhantes coincidentes com as do hidrogénio, com uma das do magnésio e aproximadamente coincidentes com as do sódio", sem qualquer menção ao hipotético hélio. Este ainda teria de esperar até 1895 para se ver reconhecido como novo elemento, em consequência do seu isolamento na Terra. Até lá não passaria de mais um dos elementos fantasma em que a Análise Espectral foi fértil (Quadro II).

\section{AGRADECIMENTOS}

À Dria Alfredina do Campo, pelo auxilio prestado nas pesquisas bibliográficas realizadas no Observatório da Ajuda, e ao Dr. John Hearnshaw (Universidade de Canterbury, Christchurch, Nova Zelândia), por informações sobre N. Pogson.

Quadro I. Elementos descobertos por análise espectral

\begin{tabular}{|c|c|c|c|c|}
\hline NOME & SIGNIFICADO & SÍmbolo & DATA & DESCOBRIDOR \\
\hline CÉSIO & $\begin{array}{l}\text { L. caesius, azul } \\
\text { celeste (das duas } \\
\text { riscas azuis) }\end{array}$ & Cs & 1860 & Bunsen e Kirchihoff \\
\hline RUBíDIO & $\begin{array}{l}\text { L. rubidius, } \\
\text { vermelho (das, duas } \\
\text { riscas vermelhas) }\end{array}$ & $\mathrm{Rb}$ & 1861 & Bunsen e Kirchhoff \\
\hline TALLIO & $\begin{array}{l}\text { G. thallos, talo } \\
\text { (da risca verde) }\end{array}$ & $\pi$ & 1861 & Crookes e Lamy \\
\hline INDIO & $\begin{array}{l}\text { indigo, azul } \\
\text { (da risca azul) }\end{array}$ & In & 1863 & Reich e Richter \\
\hline HÉLIO & $\begin{array}{l}\text { G. helios, Sol } \\
\text { (observado } \\
\text { no Sol) }\end{array}$ & $\mathrm{He}$ & 1868 & Lockyer \\
\hline GÁLIO & $\begin{array}{l}\text { L. Gallia, Gália } \\
\text { (França) }\end{array}$ & Ga & 1875 & Boisbaudran \\
\hline HÓLMIO & $\begin{array}{l}\text { L. Holmia, } \\
\text { Estocolmo }\end{array}$ & Ho & 1878 & $\begin{array}{l}\text { Delatontaine e } \\
\text { Soret }\end{array}$ \\
\hline SAMÁRIO & $\begin{array}{c}\text { samarskite, } \\
\text { mineral }\end{array}$ & Sm & 1879 & Boisbaudran \\
\hline DISPRÓSIO & $\begin{array}{l}\text { G. dysprositos, } \\
\text { dificil de obter }\end{array}$ & Dy & 1886 & Boisbaudran \\
\hline EURÓPIO & de Europa & Eu & $\begin{array}{l}1890 \\
1901\end{array}$ & $\begin{array}{l}\text { Boisbaudran } \\
\text { Demarçay }\end{array}$ \\
\hline
\end{tabular}

Quadro II. Alguns elementos inexistentes sugeridos pela Análise Espectral

\begin{tabular}{|c|c|c|c|}
\hline NOME PHOPOSTO & $\begin{array}{l}\text { PISCAS } \\
\text { CARACTERISTICAS * }\end{array}$ & $\begin{array}{l}\text { PRIMEIRAA } \\
\text { OBSEAVACCAO * }\end{array}$ & ATRIBUIÇAO CORRECTA \\
\hline HELLOO & $\begin{array}{l}447 \cdot 1: 471 \cdot 3 \cdot 587.6\left(D_{3}\right) ; \\
706.5 .1083 .0\end{array}$ & \begin{tabular}{|l} 
Protuberancias solares \\
(Herschel. Tennant. Janssen. \\
Rayat. Haid. Pogson. 1868)
\end{tabular} & $\begin{array}{l}\text { helio no estado tripleto } \\
\text { (ortohetio) }\end{array}$ \\
\hline ASTERIO & 492.2: $501.6 .667 .8^{\circ}$ & $\begin{array}{l}\text { helio oasoso } \\
\text { (Punge e Paschen, Lockyer. } \\
\text { (1895) }\end{array}$ & \begin{tabular}{|l} 
nélio no estado singuleto \\
(parantio)
\end{tabular} \\
\hline PROTOHIDROGENIO & $\begin{array}{l}\text { 454 2: 541.2: } 1012.4^{\circ} \\
\text { (serie do Pickering) }\end{array}$ & $\begin{array}{l}\text { estrela 5 Puppis } \\
\text { (Pickering. 1896) }\end{array}$ & \begin{tabular}{|l} 
hétio ionizado \\
He' \\
(Bonr, 1913)
\end{tabular} \\
\hline NEBÚLIO & $372.8: 495.9\left(N_{1}\right): 500.7\left(N_{2}\right)$ & \begin{tabular}{|l|} 
varias nebutosas gasosas \\
(Hugains 1864,1882 )
\end{tabular} & 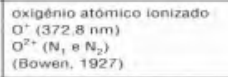 \\
\hline CORONIO & $530.3^{*}$ & $\begin{array}{l}\text { coroa solar } \\
\text { (Pogson, Rayet, 1868) }\end{array}$ & $\begin{array}{l}\text { terro ionizado, } \mathrm{Fe}^{13+} \\
\text { (Edien, 1942) }\end{array}$ \\
\hline GEOCORONIO & 557.7 & \begin{tabular}{|l|} 
auroras polares \\
\end{tabular} & \begin{tabular}{|l} 
oxigenio atómico \\
(transicato proibida) \\
(McLennan e Shrum. 1924)
\end{tabular} \\
\hline
\end{tabular}

comprimentos de onda no ar. em nm.

Os primeiros observadores nerm sempre toram os proponentes da existência do novo element.

Viamente por Lockyer na nebulosa do Orion, em 1890.

Aigumas riscas do He' toram observadas anteriormente, $r$
estreta da constelaçao do Cisne por Wolf e Rayet em 1867 .

Na regiaso visivel, observam-se muitas outras riscas menos

\section{NOTAS}

Autor do Canon dos Eclipses (1887), monumental obra que reúne parâmetros e mapas referentes a 8000 eclipses solares e 5200 eclipses lunares. cobrindo o período de 1207 a.C. a 2161 d.C. Actualmente existem programas para computadores pessoais (e.g. ECLIPSIM) que realizam os mesmos cálculos laboriosos, mas com maior rigor e em fracções de segundo.

${ }^{2}$ Notabilizou-se pelos seus estudos do efeito de Doppler em espectros estelares. Deve-se-Ihe 0 conhecido exemplo da variação de frequência do silvo da locomotiva ao passar por um observador imóvel.

${ }^{3}$ Retratado no conhecido filme "O Rei e Eu" (The King and I, 1956)

${ }^{4} 0$ espectro relâmpago (assim chamado por durar alguns segundos) viria a ser observado em 1870 pelo astrónomo americano Young, durante outro eclipse total. 0 relato de Haig contém contudo uma descrição que se adapta a este, e poderá ter sido essa de facto a primeira observação. Diz Haig que imediatamente antes de o Sol reaparecer abaixo das protuberâncias que observa, 0 espectro passou a apresentar várias riscas, destacando-se uma verde e uma azul, com cerca de um quarto de altura das riscas das protuberâncias $e$ correspondendo portanto a uma camada relativamente fina.

${ }^{5}$ Note-se que se desconhecia à época que o espectro de riscas do hidrogénio era devido ao hidrogénio atómico. A própria realidade de átomos e moléculas não estava ainda bem estabelecida.

${ }^{6}$ Comprimentos de onda no ar. Os valores de Secchi e de Rayet foram recalculados a partir da posição dada em relação a D. 


\section{Estrutura electrónica e espectro do hélio}

0 átomo de hélio possui dois electrões, tendo a configuração $1 \mathrm{~s}^{2}$ no estado fundamental. Os seus niveis de energia electrónica não são passiveis de cálculo exacto, mesmo com base na equação de Schrödinger, pois o problema de três corpos em interacção (núcleo e dois electrões) não tem solução analítica. No entanto, a aplicação de métodos de resolução aproximada conduz a resultados de grande exactidão. No estado fundamental 0 átomo encontra-se num estado singuleto, de spin nulo. Nos estados excitados, os dois electrōes podem estar ou não emparelhados. tendo-se assim estados singuleto e estados tripleto. No diagrama, mostram-se algumas transições importantes entre estados. Estas conduzem a riscas nos espectros de absorção e de emissão. As transições radiativas entre estados de dife-

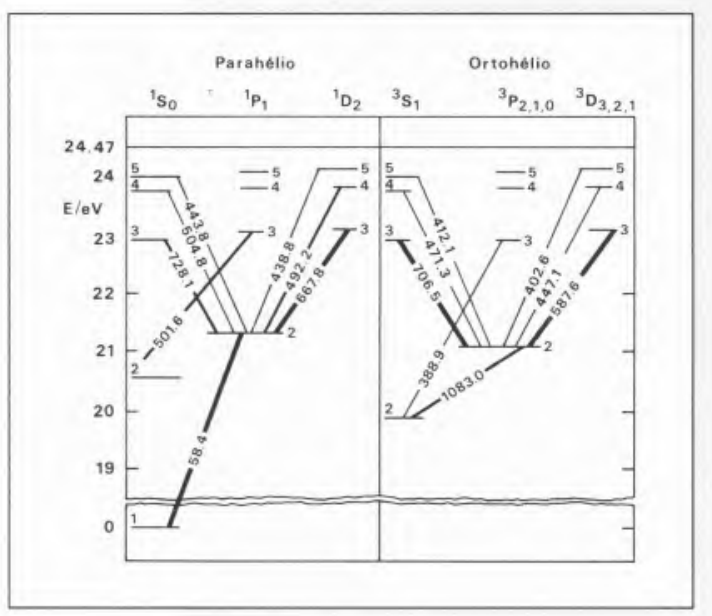

rente multiplicidade de spin (e.g singuleto-tripleto) são muito improváveis em átomo com núcleos leves, como o hélio, e praticamente não se observam. Deste modo, 0 hélio comporta-se quase como se fosse constituido por uma mistura de dois tipos de átomos: 0 parahélio (singuleto) e 0 ortohélio (tripleto). 0 hélio tripleto obtém-se do hélio singuleto (e vice-versa) por colisões inelásticas com electrões livres, para os quais as regras de selecção de transições radiativas são inválidas. Outro mecanismo de produção de ortohélio é a captura electrónica pelo lão $\mathrm{He}^{+}$, processo em que 0 estado final tanto poderá ser singuleto como tripleto. Como o hélio tripleto se comporta independentemente do hélio singuleto, estabelece-se em cada um uma distribuição de Boltzmann. Visto que 0 estado "fundamental" do hélio tripleto $\left(2^{3} \mathrm{~S}\right)$ está muito mais próximo dos estados tripleto seguintes do que 0 estado fundamental do hélio $\left(1^{1} \mathrm{~S}\right) 0$ está dos singuletos seguintes, para uma dada temperatura o hélio tripleto terá sempre muito mais átomos em estados excitados. Sendo a intensidade das riscas observadas em emissão proporcional à população dos estados de partida, as riscas mais intensas são devidas ao ortohélio, nomeadamente $1083.0 \mathrm{~nm}$, no infravermelho, $388.9 \mathrm{~nm}$, no ultravioleta, e $587.6 \mathrm{~nm}$, no laranja. Num espectrómetro de resolução média esta última risca, dita $D_{3}$, apresenta-se como um dupleto, com um espaçamento

Niveis de energia e algumas transiçōes importantes do átomo do hélio. Os comprimentos de onda associados estão dados em nm. de $0.004 \mathrm{~nm}, 0$ que é devido ao desdobramento do nivel inferior $2^{3} \mathrm{P}$ em dois $\left(2^{3} \mathrm{P}_{0}\right.$ e $\left.2^{3} \mathrm{P}_{2,1}\right)$. A pressões ou temperaturas elevadas, ou ainda sob a aç̧ão de campos magnéticos não homogéneos esta estrutura fina não é observável, pois a risca sofre um alargamento superior ao desdobamento inicial.

0 espectro de emissão do hélio apresenta ainda outras riscas na região visivel do espectro, nomeadamente 447.1 $\mathrm{nm}$ (violeta), $471.3 \mathrm{~nm}$ (azul), $706.5 \mathrm{~nm}$ (vermelha), todas devidas ao ortohélio, e ainda as riscas do parahélio a $492.2 \mathrm{~nm}$ (azul esverdeada), $501.6 \mathrm{~nm}$ (verde) e $667.8 \mathrm{~nm}$ (vermelha). As riscas do hélio são muito ténues no espectro de Fraunhofer. Pelo contrário, são intensas no espectro de emissão da cromosfera superior e das protuberâncias. A quase ausência no espectro de Fraunhofer explica-se pela temperatura relativamente bai$x a$ das partes superior da fotosfera e inferior da cromosfera, $\sim 4000 \mathrm{~K}$, insuficiente para assegurar uma fracção significativa de átomos de hélio em estados excitados a partir dos quais possa ocorrer absorção. A justificação para a intensidade elevada das riscas na emissão da cromosfera superior e protuberâncias, só recentemente estabelecida, é a excitação pela radiação $\mathrm{X}$ e ultravioleta ionizante provenientes da coroa solar: uma vez no estado tripleto, donde já não sairão, os átomos de hélio são capazes de absorver e reemitir a radiação proveniente da fotosfera, apresentando assim uma pseudo-distribuição de Boltzmann com uma temperatura de $~ 6000 \mathrm{~K}$.

\section{BIBLIOGRAFIA}

1. Revue des Cours Scientifiques 5 (1868) 183. 2. C. Wolf, Revue des Cours Scientifiques 6 (1869) 465.

3. G. Rayet, Annuaire Scientifique, Masson, Paris, 1869 .

4. Boletim do Governo do Estado da Índia 67 (1868) 370 .

5. E. Weiss, Astronomische Nachrichten (Altona) 1716 (1868)

6. Vierteljahrschrift der Astronomischen Gesellschaft (Leipzig) 7 (1872) 159.

7. J.F. Tennant, Memoirs of the Royal Astronomical Society 37 (1869) 1.

8. C.T. Haig, Proc. Roy. Soc. 17 (1868) 74.

9. J. Herschel, Proc. Roy. Soc., 17 (1868) 104.

10. Astronomische Nachrichten (Altona) 1753 (1869).
11. Monthly Notices of the Royal Astronomical Society 29 (1868) 149.

12. P. Janssen, Comptes Rendus 68 (1869) 48

13. Comptes Rendus 67 (1868) 494

14. G. Rayet, Comptes Rendus 67 (1868) 101.

15. G. Rayet, Comptes Rendus 68 (1869) 1321.

16. W. De La Rue, Monthly Notices of the Royal Astronomical Society 29 (1868) 73.

17. J.N. Lockyer, Comptes Rendus 67 (1868) 836

18. P. Janssen, Comptes Rendus 67 (1868) 838.

19. P. Janssen, Comptes Rendus 68 (1869) 367.

20. H. Faye, Comptes Rendus 67 (1868) 840.

21. A. Secchi, Comptes Rendus 67 (1868) 437.

22. A. Secchi, Comptes Rendus 67 (1868) 1123.

23. G. Rayet, Comptes Rendus 68 (1869) 320.

24. E. Frankland, J.N. Lockyer, Comptes Rendus 68 (1869) 420

25. J.N. Lockyer, Inorganic Evolution as Studied by Spectrum Analysis, McMillan, Londres, 1900. 26. J.N. Lockyer, Comptes Rendus 88 (1879) 148.

27. W. Thomson, Nature 4 (1871) 262.

28. E. Willm, M. Hanriot, Traité de Chimie Minérale et Organique, Masson, Paris, 1889.

\section{REFERÊNCIAS GERAIS}

P. Couderc, Les Éclipses, Que sais-je?, PUF, 1961. H. Zirin, Astrophysics of the Sun, Cambridge UP, 1989.

J.B. Hearnshaw, The Analysis of Starlight, Cambridge UP, 1990

* Instituto Superior Técnico 

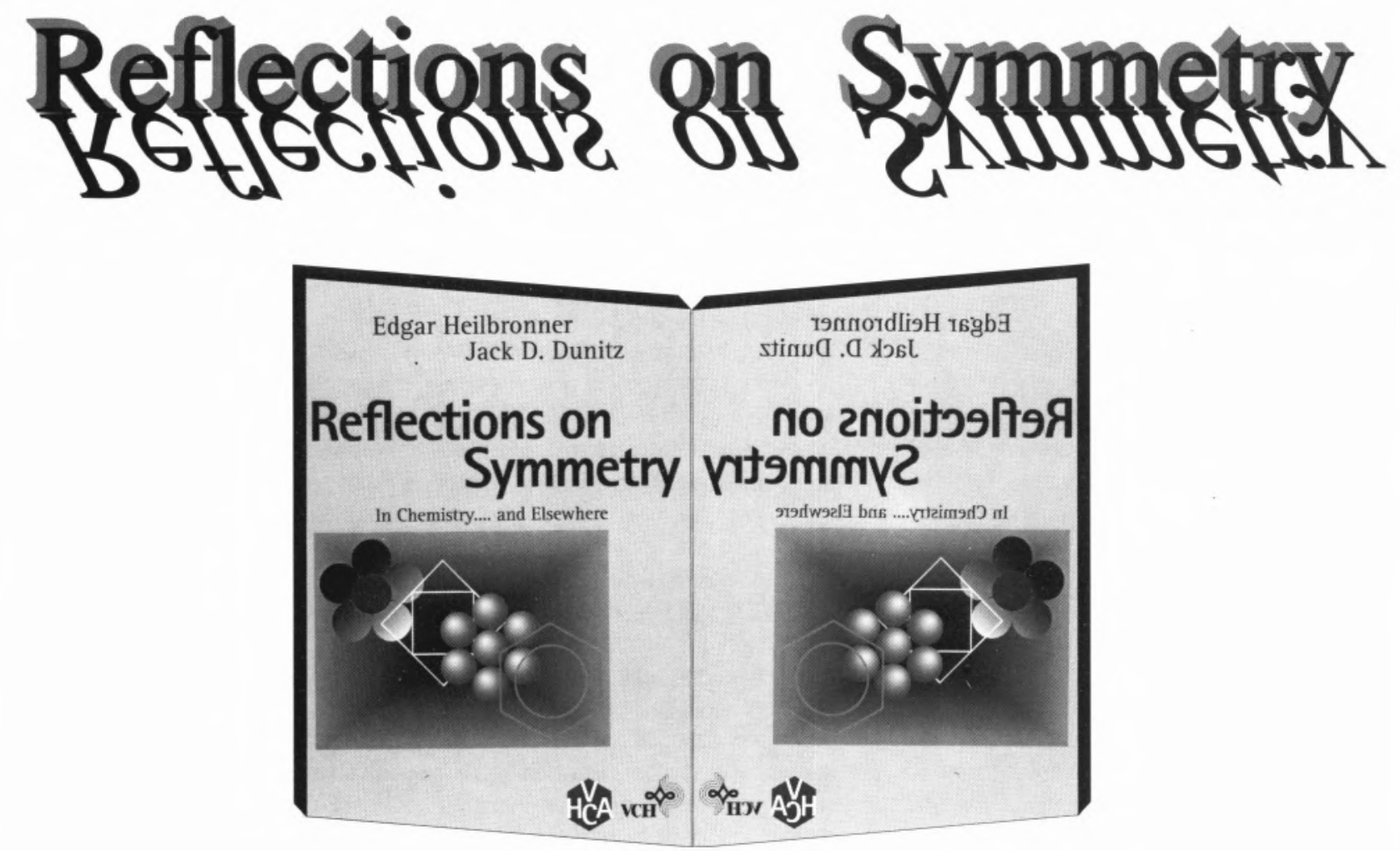

1992. Ca 168 pages with ca 118 figures.

Hardcover. DM 58.00.

ISBN 3-527-28488-5 (VCH, Weinheim)

What do Schrödinger's wave functions, Escher's intricate tiling patterns and chemistry's latest marvel, buckminsterfullerene, have in common?

This stunning book, written by two world-famous scientists, introduces the reader to one of nature's most fundamental, and ubiquitous, phenomena: Symmetry.

Enormous in scope, this scientific tour-de-force covers topics as diverse as quantum mechanics, stereochemistry, Penrose tilings and Raphael's
Madonna. The authors connect these apparently unrelated fields in a completely non-mathematical fashion, which should appeal to the general and specialist reader alike.

Lucidly written and beautifully illustrated, this book provides an eminently readable discussion of the omnipresent concept of symmetry, its application in all branches of science, and its perception in nature, art and elsewhere.

Hoffmann, R.

\section{Solids and Surfaces}

A Chemist's View of Bonding in

Extended Structures

1989. 142 pages with 177 figures and

4 tables.

Hardcover. DM 48.00.

ISBN 3-527-26905-3 (VCH, New York)

To order please contact your bookseller or:

VCH, P.O. Box 1011 61, D-6940 Weinheim, Fax 06201- 606184

VCH, Hardstrasse 10, P.O. Box, CH-4020 Basel

VCH, 8 Wellington Court, Cambridge CB1 1HZ, UK

VCH, 220 East 23rd Street, New York, NY 10010-4606, USA (toll free: 1-800-367-8249)

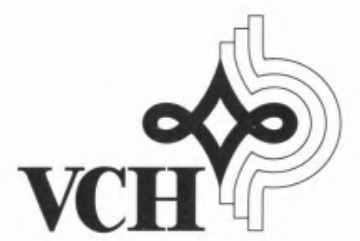

